\title{
Novel Nortriterpenoids from Aphanamixis grandifolia
}

\author{
Yao Zhang, Jun-Song Wang, Jun Luo, and Ling-Yi Kong* \\ Department of Natural Medicinal Chemistry, China Pharmaceutical University; 24 Tong Jia Xiang, Nanjing 210009, \\ People's Republic of China. \\ Received September 11, 2010; accepted November 1, 2010; published online November 8, 2010
}

Four novel nortriterpenoids, 24,25-epoxy-tirucall-7,20(E)-diene-3,23-dione (1), 24,25,26,27-tetranortirucall1,7-diene-23(21)-lactone (2), 3 $\alpha$-hydroxy-tirucall-7-ene-20-one (3), and 3-oxo-tirucall-7-ene-3,20-dione (4), together with one known compound mombasol (5) were isolated from the stem barks of Aphanamixis grandifolia. Their structures were elucidated on the basis of various spectroscopic analysis including electrospray ionization (ESI)-MS, high resolution (HR)-ESI-MS, IR, 1D- and 2D-NMR techniques (heteronuclear single quantum coherence (HSQC), heteronuclear multiple bond connectivity (HMBC) and rotating frame Overhauser enhancement spectroscopy (ROESY)), and by comparison of their spectral data with those reported. The absolute configuration of compound 1 was determined by circular dichroism (CD) exciton chirality.

Key words Aphanamixis grandifolia; Meliaceae; nortriterpenoid

Species of the genus Aphanamixis (Meliaceae) are sources of various secondary metabolites with interesting diverse chemical structures. Previous chemical investigations on Aphanamixis have led to the isolation of a series of limonoids, ${ }^{1-5)}$ tirucallane triterpenoids, ${ }^{6}$ diterpenoids, ${ }^{77}$ sesquiterpenoids, ${ }^{8)}$ and flavone glycosides. ${ }^{9)}$ As a part of our continuous interest in the Meliaceae family, ${ }^{10-12)}$ four new tirucallane-type nortriterpenoids, 24,25-epoxy-tirucall7,20(E)-diene-3,23-dione (1), 24,25,26,27-tetranortirucall1,7-diene-23(21)-lactone (2), $3 \alpha$-hydroxy-tirucall-7-ene-20one (3), and 3-oxo-tirucall-7-ene-3,20-dione (4), along with a known highly complex oxidized limonoid, mombasol (5), ${ }^{13)}$ were isolated from the EtOH exact of the stem barks of Aphanamixis grandifolia BL., a timer tree mainly distributed in the tropical areas of Asia such as southern China, Malaysia, Indonesia and India. ${ }^{14)}$ In this paper, we describe the isolation and structural elucidation of these compounds.

\section{Results and Discussion}

Compound 1 was obtained as a white, amorphous powder. Its positive high resolution-electrospray ionization (HR-ESI)MS showed a quasi-molecular ion at $\mathrm{m} / \mathrm{z} 461.3028[\mathrm{M}+\mathrm{Na}]^{+}$ (Calcd for $\mathrm{C}_{29} \mathrm{H}_{42} \mathrm{O}_{3} \mathrm{Na}, 461.3026$ ), which indicated that it has a molecular formula of $\mathrm{C}_{29} \mathrm{H}_{42} \mathrm{O}_{3}$ with nine degrees of unsaturation. The ${ }^{1} \mathrm{H}$ - and ${ }^{13} \mathrm{C}$-NMR spectra (Table 1) exhib-

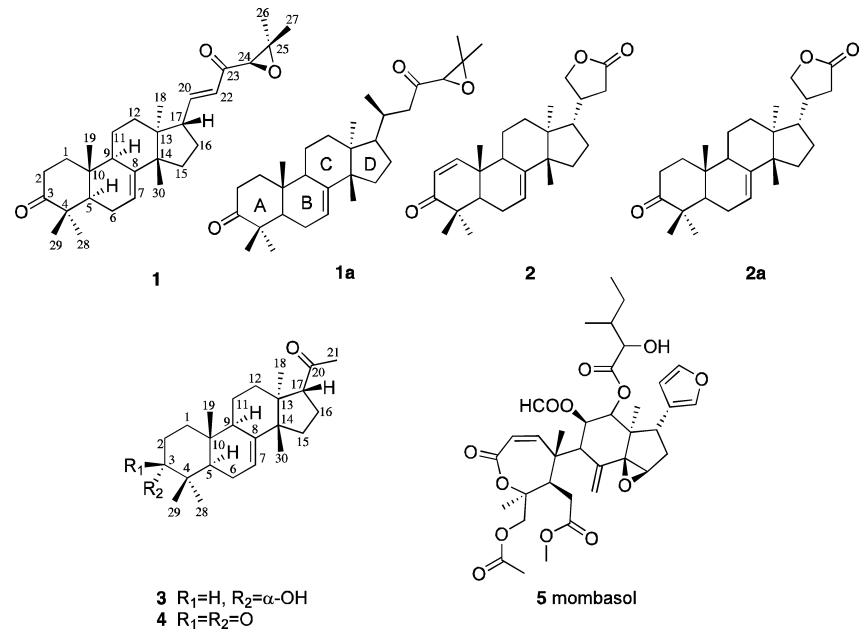

Table 1. ${ }^{1} \mathrm{H}-(500 \mathrm{MHz})$ and ${ }^{13} \mathrm{C}-\mathrm{NMR}(125 \mathrm{MHz})$ Spectral Data of $\mathbf{1}$ and 2 in $\mathrm{CDCl}_{3}(\delta$ in ppm)

\begin{tabular}{|c|c|c|c|c|}
\hline \multirow{2}{*}{ No. } & \multicolumn{2}{|r|}{1} & \multicolumn{2}{|r|}{2} \\
\hline & $\delta_{\mathrm{C}}$ & $\delta_{\mathrm{H}}($ multi, $J$ in $\mathrm{Hz})$ & $\delta_{\mathrm{C}}$ & $\delta_{\mathrm{H}}($ multi, $J$ in $\mathrm{Hz})$ \\
\hline $1 \alpha$ & $38.5(\mathrm{t})$ & $1.45(*)$ & $154.7(d)$ & $6.88(\mathrm{~d}, 10.4)$ \\
\hline $1 \beta$ & - & $1.98(*)$ & - & - \\
\hline $2 \alpha$ & $34.9(\mathrm{t})$ & $2.25(\mathrm{dt}, 14.5,3.0)$ & $125.9(\mathrm{~d})$ & $5.91(\mathrm{~d}, 10.4)$ \\
\hline $2 \beta$ & - & $2.75(\mathrm{td}, 14.5,5.5)$ & - & - \\
\hline 3 & $216.5(\mathrm{~s})$ & - & 204.7 (s) & - \\
\hline 4 & $47.9(\mathrm{~s})$ & - & 44.3 (s) & - \\
\hline $5 \alpha$ & $52.4(d)$ & $1.73(*)$ & $48.6(\mathrm{~d})$ & $2.09(*)$ \\
\hline $6 \alpha$ & $24.4(\mathrm{t})$ & $2.11(\mathrm{~m})$ & $23.6(\mathrm{t})$ & $2.09(*)$ \\
\hline $6 \beta$ & - & $2.11(\mathrm{~m})$ & - & $2.17(\mathrm{~m})$ \\
\hline 7 & $118.9(\mathrm{~d})$ & $5.35(\mathrm{dd}, 6.5,3.0)$ & $119.9(d)$ & $5.43(\mathrm{dd}, 6.5,2.5)$ \\
\hline 8 & $144.8(\mathrm{~s})$ & - & $144.5(\mathrm{~s})$ & - \\
\hline $9 \alpha$ & $48.4(\mathrm{~d})$ & $\begin{array}{c}2.29(\mathrm{ddt}, 13.0 \\
6.5,3.0)\end{array}$ & $45.5(\mathrm{~d})$ & $2.54(*)$ \\
\hline 10 & $35.2(\mathrm{~s})$ & - & $37.9(\mathrm{~d})$ & - \\
\hline $11 \alpha$ & $17.5(\mathrm{t})$ & $1.62(\mathrm{~m})$ & $17.8(t)$ & $1.70(\mathrm{~m})$ \\
\hline $11 \beta$ & - & $1.62(\mathrm{~m})$ & - & $1.80(\mathrm{~m})$ \\
\hline $12 \alpha$ & $30.5(\mathrm{t})$ & $1.48(*)$ & $31.9(\mathrm{t})$ & $1.48(\mathrm{~m})$ \\
\hline $12 \beta$ & - & $1.75(*)$ & - & $1.79(\mathrm{~m})$ \\
\hline 13 & $46.6(\mathrm{~s})$ & - & $43.6(\mathrm{~s})$ & - \\
\hline 14 & $50.7(\mathrm{~s})$ & - & $51.0(\mathrm{~s})$ & - \\
\hline $15 \alpha$ & $34.7(\mathrm{t})$ & $1.65(\mathrm{~m})$ & $34.4(\mathrm{t})$ & $1.61(\mathrm{~m})$ \\
\hline $15 \beta$ & - & $1.71(*)$ & - & $1.61(\mathrm{~m})$ \\
\hline $16 \alpha$ & $26.7(\mathrm{t})$ & $1.72(*)$ & $27.3(\mathrm{t})$ & $1.35(\mathrm{~m})$ \\
\hline $16 \beta$ & - & $1.98(*)$ & & $1.97(\mathrm{~m})$ \\
\hline $17 \beta$ & $51.2(\mathrm{~d})$ & $2.57(\mathrm{~m})$ & $51.0(\mathrm{~d})$ & $1.79(\mathrm{~m})$ \\
\hline $18 \alpha$ & $23.3(q)$ & $0.82(\mathrm{~s})$ & $22.8(q)$ & $0.86(\mathrm{~s})$ \\
\hline $19 \beta$ & $12.7(q)$ & $1.02(\mathrm{~s})$ & $13.5(q)$ & $1.04(\mathrm{~s})$ \\
\hline 20 & $152.1(\mathrm{~d})$ & $7.05(\mathrm{dd}, 16.0,7.5)$ & 39.1 (d) & $2.54(*)$ \\
\hline $21 \mathrm{a}$ & - & - & $72.3(\mathrm{t})$ & $4.38(\mathrm{t}, 8.5)$ \\
\hline $21 b$ & - & - & - & $3.93(\mathrm{t}, 9.0)$ \\
\hline 22 & $127.1(\mathrm{~d})$ & $6.34(\mathrm{dd}, 16.0,1.5)$ & $34.6(\mathrm{t})$ & $2.54(*)$ \\
\hline 23 & $194.9(\mathrm{~s})$ & - & $176.8(\mathrm{~s})$ & $2.20(\mathrm{~m})$ \\
\hline $24 \alpha$ & $65.2(\mathrm{~d})$ & $3.48(\mathrm{~s})$ & - & - \\
\hline 25 & $60.8(\mathrm{~s})$ & - & - & - \\
\hline $26 \alpha$ & $24.8(q)$ & $1.45(\mathrm{~s})$ & - & - \\
\hline $27 \beta$ & $18.8(q)$ & $1.27(\mathrm{~s})$ & - & - \\
\hline $28 \alpha$ & $24.6(q)$ & $1.05(\mathrm{~s})$ & $24.2(q)$ & $1.13(\mathrm{~s})$ \\
\hline $29 \beta$ & $21.6(q)$ & $1.12(\mathrm{~s})$ & $21.4(q)$ & $1.09(\mathrm{~s})$ \\
\hline $30 \beta$ & $27.3(q)$ & $1.05(\mathrm{~s})$ & $27.7(q)$ & $1.07(\mathrm{~s})$ \\
\hline
\end{tabular}

* Signal pattern unclear due to overlapping. 
ited resonances for seven methyl groups $\left[\delta_{\mathrm{H}} 0.82,1.02,1.05\right.$, $1.05,1.12,1.27$ and 1.45 (each $3 \mathrm{H}, \mathrm{s}$ ); $\delta_{\mathrm{C}} 23.3,12.7,24.6$, 27.3, 21.6, 18.8, 24.8 (each q)], a trisubstituted double bond $\left[\delta_{\mathrm{H}} 5.35(1 \mathrm{H}, \mathrm{dd}, J=6.5,3.0 \mathrm{~Hz}) ; \delta_{\mathrm{C}} 118.9(\mathrm{~d}), 144.8(\mathrm{~s})\right]$, an $\alpha, \beta$-unsaturated ketone $\left[\delta_{\mathrm{H}} 6.34(1 \mathrm{H}, \mathrm{dd}, J=16.0,1.5 \mathrm{~Hz}, \mathrm{H}-\right.$ 22), 7.05 (1H, dd, $J=16.0,7.5 \mathrm{~Hz}, \mathrm{H}-20$ ); $\delta_{\mathrm{C}} 127.1$ (d), 152.1 (d), $194.9(\mathrm{~s})]$ and a characteristic epoxy group $\left[\delta_{\mathrm{H}} 3.48(1 \mathrm{H}\right.$, s), $\left.\delta_{\mathrm{C}} 65.2(\mathrm{~d}), 60.8(\mathrm{~s})\right]$ in addition to seven methylene carbons, seven methine carbons, and eight quaternary carbons. The four olefinic carbons, two ketone carbons, and one epoxy ring account for five degrees of unsaturation. The remaining four degrees of unsaturation suggested that the molecule contains four rings in core carbon skeleton. After assignment of all the protons to their directly bonded carbons from heteronuclear single quantum coherence (HSQC), the total structural skeleton of $\mathbf{1}$ was established by heteronuclear multiple bond connectivity (HMBC) and rotating frame Overhauser enhancement spectroscopy (ROESY) correlations. The connectivity of Me-18 to C-13, Me-19 to C-10, $\mathrm{Me}-28$ and Me-29 to C-4 and Me-30 to C-14 were determined from the following $\mathrm{HMBC}$ long-range correlations (Fig. 1): Me-18 at $\delta_{\mathrm{H}} 0.82$ with $\mathrm{C}-12, \mathrm{C}-14$ and $\mathrm{C}-17$; Me-19 at $\delta_{\mathrm{H}} 1.02$ with C-1, C-5 and C-9; Me-30 at $\delta_{\mathrm{H}} 1.05$ with C-8 and $\mathrm{C}-15$; and two gem-dimethyl (Me-28 and Me-29) at $\delta_{\mathrm{H}}$ 1.05 and 1.12 with a ketone carbonyl (C-3) at $\delta_{\mathrm{C}} 216.5$. These data suggested 1 has a 3 -oxo- $\Delta^{7}$-tetracyclic skeleton. ${ }^{15,16)}$ The NMR spectra (Table 1) of $\mathbf{1}$ were similar to that of $1 \mathbf{a},{ }^{17)}$ with the major differences being the loss of a doublet methyl carbon in side-chain and instead, the appearances of a trans-double bond and an upfield shifted carbonyl carbon signal at $\delta_{\mathrm{C}} 194.9(\mathrm{C}-23)$, suggesting the existence of an $\alpha, \beta$-unsaturated ketone in the side-chain of $\mathbf{1}$, which was confirmed by the HMBC correlations observed from the two olefinic protons ( $\mathrm{H}-20$ and $\mathrm{H}-22)$ to the carbonyl carbon (C$23)$, placing the trans-double bond at $\mathrm{C}-20$ and $\mathrm{C}-22$. The HMBC cross-peaks from the epoxylated singlet proton at $\delta_{\mathrm{H}}$ 3.48 to C-23, C-25 and two terminal methyl signals (C-26 and C-27) assigned a 24,25-epoxy group in the side-chain. The linkage of the side-chain to the tetracyclic core skeleton between $\mathrm{C}-17$ and $\mathrm{C}-20$ was also confirmed by HMBC corre- lation between $\mathrm{H}-20$ and $\mathrm{C}-17$. The planar structure of $\mathbf{1}$ was thus established as shown.

The relative configuration of $\mathbf{1}$ was determined by a ROESY experiment (Fig. 2). The ROESY correlations of H5 with $\mathrm{H}-9$ and Me-28, and Me-18 with $\mathrm{H}-9$ and Me-26 $\left(\delta_{\mathrm{H}}\right.$ 1.45), indicated that H-5, H-9, Me-18, Me-26 and Me-28 were confacial and arbitrarily assigned as $\alpha$-oriented. The ROESY correlation between $\mathrm{H}-24$ and Me-26 assigned an $\alpha$ orientation to $\mathrm{H}-24$, thus the $\beta$-orientation to the 24,25 -epoxy group, which was also consistent with that of cordialin A acetate, a compound with similar side-chain, confirmed by Xray analysis. ${ }^{18)}$ The nuclear Overhauser effect (NOE) correlations between $\mathrm{H}-17$ and Me-30 helped the determination of $\mathrm{H}-17$ as $\beta$-orientated. The structure of $\mathbf{1}$ was thus established as 24,25-epoxy-tirucall-7,20 (E)-diene-3,23-dione.

The absolute configuration of $\mathbf{1}$ (Fig. 3) was determined by

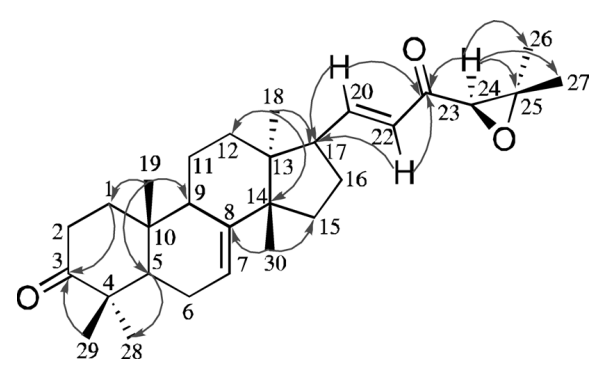

Fig. 1. Key $\mathrm{HMBC}(\mathrm{H} \rightarrow \mathrm{C})$ Correlations of $\mathbf{1}$

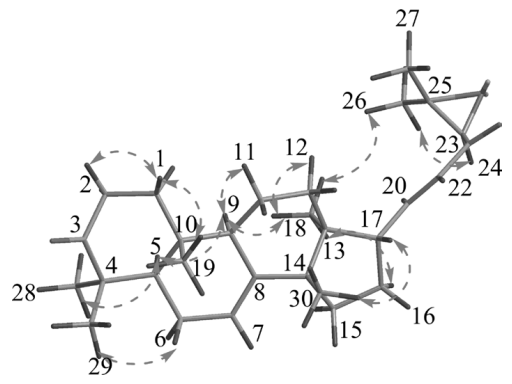

Fig. 2. Selected ROESY Correlations of $\mathbf{1}$

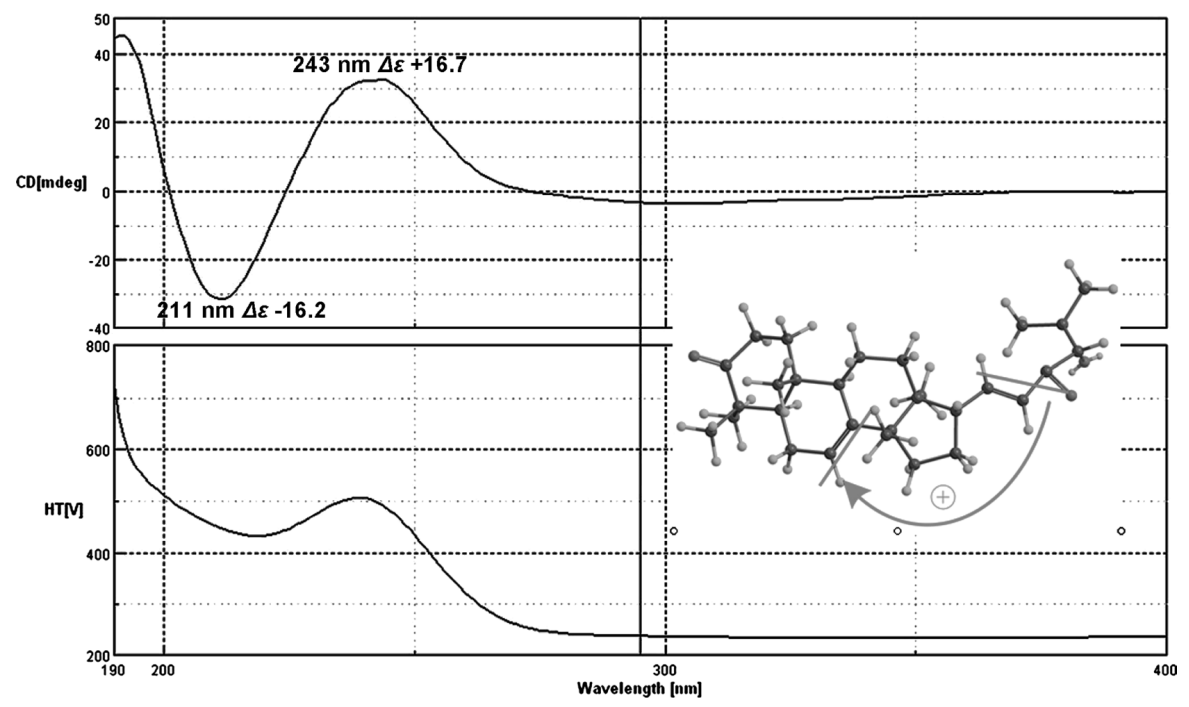

Fig. 3. CD and UV Spectra of $\mathbf{1}$

Bold lines denote the electrictransition dipole of the chromophores. 


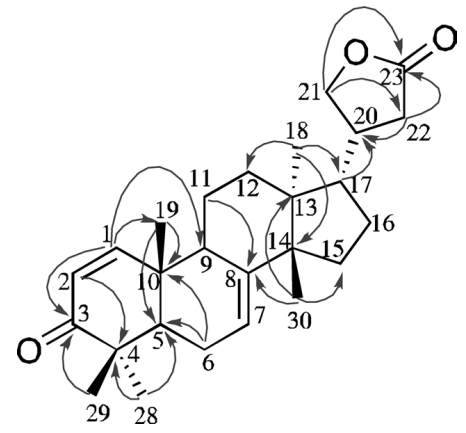

Fig. 4. Key $\operatorname{HMBC}(\mathrm{H} \rightarrow \mathrm{C})$ Correlations of 2

the circular dichroism (CD) exciton chirality method. The CD spectrum of 1 revealed a negative Cotton effect at $\lambda_{\max }$ $211 \mathrm{~nm}(\Delta \varepsilon-16.2)$ and a positive Cotton effect at $\lambda_{\max }$ $243 \mathrm{~nm}(\Delta \varepsilon+16.7)$ due to the transition interaction between two different chromophores of the $\Delta^{7(8)}$ double bond ${ }^{19)}$ and $\alpha, \beta$-unsaturated ketone, ${ }^{20)}$ indicating a positive chirality for 1 , thus determined the absolute configuration as depicted.

Compound 2 had the molecular formula $\mathrm{C}_{26} \mathrm{H}_{36} \mathrm{O}_{3}$ as inferred from its high resolution mass spectrum, indicating nine degrees of unsaturation. The IR spectrum showed two strong absorption bands due to carbonyl $\left(1782 \mathrm{~cm}^{-1}\right)$ and double bond $\left(1675 \mathrm{~cm}^{-1}\right)$. The ${ }^{13} \mathrm{C}$-NMR spectrum resolved 26 carbon resonances, classified into five methyls, seven methylenes (one oxygenated), seven methines (three olefinic carbons), and seven quaternary carbons (two carbonyl and one olefinic carbons) with the help of HSQC experiment. The aforementioned NMR data indicated that four out of the seven degrees of unsaturation come from two carbon-carbon double bonds and two carbonyls. The remaining five degrees of unsaturation required 2 to comprise five rings. The NMR spectra of $\mathbf{2}$ exhibited the characteristic signals of an $\alpha, \beta$-unsaturated ketone $\left[\delta_{\mathrm{H}} 6.88(1 \mathrm{H}, \mathrm{d}, J=10.4 \mathrm{~Hz})\right.$ and $5.91(1 \mathrm{H}$, d, $J=10.4 \mathrm{~Hz}$ ), $\delta_{\mathrm{C}} 154.7$ (d), 125.9 (d) and 204.7 (s)]. This unit was confirmed by the HMBC correlations (Fig. 4) from the two down-field shifted olefinic protons to the ketone carbon signal at $\delta_{\mathrm{C}} 204.7$, which showed cross-peaks with the two gem-methyl protons at $\delta_{\mathrm{H}} 1.13$ and 1.09 (each $3 \mathrm{H}, \mathrm{s}$ ), suggesting the presence of a ketone group at C-3 position and thus an $\alpha, \beta$-unsaturated ketone structure in ring $\mathrm{A}$. Both the gem-dimethyl and the $\mathrm{C}-3$ signals correlated in the HMBC spectrum to the carbon signal at $\delta_{\mathrm{C}} 48.6$, coupled to a methine signal at $\delta_{\mathrm{H}} 2.09$ in the HSQC spectrum and is, hence, assigned to $\mathrm{C}-5$, which in turn exhibited correlation with the olefinic proton (H-7). A $\gamma$-lactone nature of the sidechain and its position at $\mathrm{C}-17$ were suggested by the HMBC long-range cross-peaks from protons at $\delta_{\mathrm{H}} 4.38(1 \mathrm{H}, \mathrm{t}$, $J=8.5 \mathrm{~Hz}, \mathrm{H}-21 \mathrm{a})$ and $3.93(1 \mathrm{H}, \mathrm{t}, J=9.0 \mathrm{~Hz}, \mathrm{H}-21 \mathrm{~b})$ to C$17, \mathrm{C}-20$ and $\mathrm{C}-23$, and from $\mathrm{H}-17$ to $\mathrm{C}-20$ and C-22. Comprehensive analysis of the 2D-NMR data, especially HMBC (Fig. 4), allowed the establishment of the planar structure of $\mathbf{2}$, similar to $\mathbf{2} \mathbf{a}^{21)}$ with a saturated ketone in ring A. The relative configurations of $\mathbf{2}$ were determined to be the same as those of $\mathbf{2 a}$ by ROESY spectrum in a way similar to $\mathbf{1}$. Therefore, the whole structure of $\mathbf{2}$ was established as depicted.

Compound 3 gave a molecular formula of $\mathrm{C}_{24} \mathrm{H}_{38} \mathrm{O}_{2}$ (six degrees of unsaturation), established by the HR-ESI-MS
Table 2. ${ }^{1} \mathrm{H}-(500 \mathrm{MHz})$ and ${ }^{13} \mathrm{C}-\mathrm{NMR}(125 \mathrm{MHz})$ Spectral Data of 3 and 4 in $\mathrm{CDCl}_{3}(\delta$ in ppm)

\begin{tabular}{|c|c|c|c|c|}
\hline \multirow{2}{*}{ No. } & \multicolumn{2}{|r|}{3} & \multicolumn{2}{|r|}{4} \\
\hline & $\delta_{\mathrm{C}}$ & $\delta_{\mathrm{H}}($ multi, $J$ in $\mathrm{Hz})$ & $\delta_{\mathrm{C}}$ & $\delta_{\mathrm{H}}($ multi, $J$ in $\mathrm{Hz}$ ) \\
\hline $1 \alpha$ & $31.2(\mathrm{t})$ & $1.48(\mathrm{~m})$ & $38.4(t)$ & $1.47(\mathrm{td}, 14.0,4.0)$ \\
\hline $1 \beta$ & - & $1.37(\mathrm{~m})$ & - & $\begin{array}{c}2.00 \text { (ddd, } 14.0 \\
5.5,4.0)\end{array}$ \\
\hline $2 \alpha$ & $25.4(\mathrm{t})$ & $1.63(*)$ & $34.8(\mathrm{t})$ & $2.25(*)$ \\
\hline $2 \beta$ & - & $1.93(*)$ & - & $2.76(\mathrm{td}, 14.5,5.5)$ \\
\hline $3 \beta$ & 76.2 (d) & $3.46(\mathrm{t}, 2.8)$ & $216.4(\mathrm{~s})$ & - \\
\hline 4 & $37.4(\mathrm{~s})$ & - & $47.8(\mathrm{~s})$ & - \\
\hline $5 \alpha$ & 44.6 (d) & $1.77(*)$ & $52.2(\mathrm{~d})$ & $1.73(*)$ \\
\hline $6 \alpha$ & $23.9(\mathrm{t})$ & $1.95(*)$ & $24.3(\mathrm{t})$ & $2.10(*)$ \\
\hline $6 \beta$ & - & $2.05(\mathrm{~m})$ & - & $2.10(*)$ \\
\hline 7 & 119.1 (d) & $5.29(\mathrm{dd}, 6.5,3.5)$ & 119.0 (d) & $5.35(\mathrm{dd}, 6.5,3.5)$ \\
\hline 8 & $144.5(\mathrm{~s})$ & - & $144.3(\mathrm{~s})$ & - \\
\hline $9 \alpha$ & $48.3(\mathrm{~d})$ & $2.33(\mathrm{~m})$ & $48.1(\mathrm{~d})$ & $2.28(*)$ \\
\hline 10 & $34.8(\mathrm{~s})$ & - & $35.1(\mathrm{~s})$ & - \\
\hline $11 \alpha$ & $17.5(\mathrm{t})$ & $1.59(\mathrm{~m})$ & $17.7(t)$ & $1.67(\mathrm{~m})$ \\
\hline $11 \beta$ & - & $1.68(\mathrm{~m})$ & - & $1.67(\mathrm{~m})$ \\
\hline $12 \alpha$ & $32.5(\mathrm{t})$ & $1.76(*)$ & $32.3(\mathrm{t})$ & $1.79(\mathrm{~m})$ \\
\hline $12 \beta$ & - & $2.08(\mathrm{~m})$ & - & $2.12(*)$ \\
\hline 13 & $45.0(\mathrm{~s})$ & - & 44.9 (s) & - \\
\hline 14 & $51.7(\mathrm{~s})$ & - & $51.6(\mathrm{~s})$ & - \\
\hline $15 \alpha$ & $34.0(t)$ & $1.62(*)$ & $34.0(t)$ & $1.60(\mathrm{~m})$ \\
\hline $15 \beta$ & - & $1.54(\mathrm{~m})$ & - & $1.60(\mathrm{~m})$ \\
\hline $16 \alpha$ & $21.9(\mathrm{t})$ & $1.72(\mathrm{~m})$ & $21.9(\mathrm{t})$ & $1.74(*)$ \\
\hline $16 \beta$ & - & $2.26(\mathrm{~m})$ & - & $2.27(*)$ \\
\hline $17 \beta$ & $61.6(\mathrm{~d})$ & $2.82(\mathrm{dd}, 9.0,8.5)$ & $61.5(\mathrm{~d})$ & $2.83(\mathrm{dd}, 9.0,8.5)$ \\
\hline $18 \alpha$ & $23.2(q)$ & $0.76(\mathrm{~s})$ & $23.2(\mathrm{q})$ & $0.75(\mathrm{~s})$ \\
\hline $19 \beta$ & $13.0(q)$ & $0.80(\mathrm{~s})$ & $12.7(q)$ & $1.03(\mathrm{~s})$ \\
\hline 20 & $210.0(\mathrm{~s})$ & - & $209.7(\mathrm{~s})$ & - \\
\hline 21 & $31.0(q)$ & $2.11(\mathrm{~s})$ & $30.9(q)$ & $2.12(\mathrm{~s})$ \\
\hline $28 \alpha$ & $27.8(\mathrm{q})$ & $0.93(\mathrm{~s})$ & $24.5(\mathrm{q})$ & $1.05(\mathrm{~s})$ \\
\hline $29 \beta$ & $21.8(\mathrm{q})$ & $0.92(\mathrm{~s})$ & $21.5(\mathrm{q})$ & $1.12(\mathrm{~s})$ \\
\hline $30 \beta$ & $27.1(\mathrm{q})$ & $1.05(\mathrm{~s})$ & $27.2(q)$ & $1.08(\mathrm{~s})$ \\
\hline
\end{tabular}

* Signal pattern unclear due to overlapping.

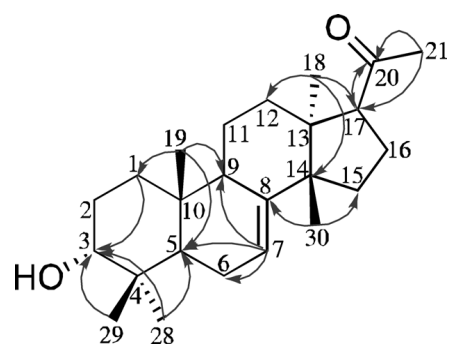

Fig. 5. Key HMBC $(\mathrm{H} \rightarrow \mathrm{C})$ Correlations of $\mathbf{3}$

pseudo-molecular ion at $\mathrm{m} / z 381.2769[\mathrm{M}+\mathrm{Na}]^{+}$(Calcd for $\mathrm{C}_{24} \mathrm{H}_{38} \mathrm{O}_{2} \mathrm{Na}, 381.2764$ ). The ${ }^{1} \mathrm{H}-$ and ${ }^{13} \mathrm{C}-\mathrm{NMR}$ of 3 (Table 2) showed 24 signals for six tertiary methyls $\left(\delta_{\mathrm{C}} 13.0,21.8\right.$, $23.2,27.1,27.8$, and 31.0), seven methylenes, five methines (one oxygenated), and six quaternary carbons (one carbonyl carbon $\delta_{\mathrm{C}} 210.0$ ). Among them, signals of one downfield shifted methyl protons at $\delta_{\mathrm{H}} 2.11(3 \mathrm{H}, \mathrm{s})$, indicating the presence of a vicinal carbonyl carbon, two olefinic carbons $\left[\delta_{\mathrm{H}}\right.$ $\left.5.29(1 \mathrm{H}, \mathrm{dd}, J=6.5,3.5 \mathrm{~Hz}) ; \delta_{\mathrm{C}} 119.1(\mathrm{~d}), 144.5(\mathrm{~s})\right]$, and one oxymethine carbon $\left[\left(\delta_{\mathrm{H}} 3.46(1 \mathrm{H}, \mathrm{t}, J=2.8 \mathrm{~Hz}) ; \delta_{\mathrm{C}} 76.2\right.\right.$ (d)] were observed. These data featured a tirucallane-type triterpenoids with a double bond between C-7 and C-8, and a $3 \alpha$-hydroxy. ${ }^{16)}$

The HMBC correlations (Fig. 5) of H-3 $\left(\delta_{\mathrm{H}} 3.46\right)$ with C$1, \mathrm{C}-2$ and $\mathrm{C}-5$ confirmed the position of the $\mathrm{OH}$ at $\mathrm{C}-3$. The 


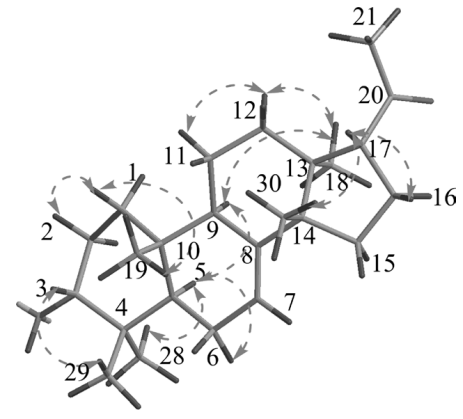

Fig. 6. Selected ROESY Correlations of $\mathbf{3}$

correlations from an olefinic proton $\left(\delta_{\mathrm{H}} 5.29, \mathrm{H}-7\right)$ to C-5, C6 , and C-9 suggested a $\Delta^{7}$ double bond. The presence of the tetracyclic core skeleton was supported by the HMBC crosspeaks from Me-18 to $\mathrm{C}-13, \mathrm{C}-14$ and $\mathrm{C}-17, \mathrm{Me}-19$ to $\mathrm{C}-1, \mathrm{C}-$ 5, C-9 and C-10, from both the gem-dimethyl (Me-28 and $\mathrm{Me}-29)$ to $\mathrm{C}-3, \mathrm{C}-4$ and $\mathrm{C}-5, \mathrm{Me}-28$ to $\mathrm{C}-29$, and $\mathrm{Me}-29$ to $\mathrm{C}-28$. The key correlations from a methyl $\left(\delta_{\mathrm{H}} 2.11, \mathrm{H}-21\right)$ to $\mathrm{C}-17$ and $\mathrm{C}-20$, and from $\mathrm{H}-17$ to $\mathrm{C}-20$ clarified the sidechain and its linkage to the tetracyclic core between $\mathrm{C}-17$ and C-20.

The relative configuration of the triterpenoid core was mainly established by a ROESY experiment (Fig. 6). The cross-peaks of Me-28 with H-5, H-5 with H-9, Me-18 with $\mathrm{H}-9$, Me-18 with $\mathrm{H}-12 \alpha$ and Me-18 with $\mathrm{H}-16 \alpha$, indicated that they were confacial and were randomly assigned as $\alpha$ orientation. The ROESY correlations between $\mathrm{Me}-29$ and $\mathrm{H}-$ 3 , Me-30 and $\mathrm{H}-17$ revealed that $\mathrm{H}-3, \mathrm{H}-17, \mathrm{Me}-29$ and Me30 were in $\beta$-orientation, and further confirmed the $\alpha$ configuration of the $\mathrm{OH}-3$. The structure of 3 was thus established as $3 \alpha$-hydroxy-tirucall-7-ene-20-one.

Compound 4 was obtained as a white amorphous powder with a molecular formula of $\mathrm{C}_{24} \mathrm{H}_{36} \mathrm{O}_{2}$ (seven drgees of unsaturation) in agreement with the HR-ESI-MS analysis $\left(\mathrm{m} / \mathrm{z} 379.2609[\mathrm{M}+\mathrm{Na}]^{+}\right.$, Calcd for $\left.\mathrm{C}_{24} \mathrm{H}_{36} \mathrm{O}_{2} \mathrm{Na}, 379.2608\right)$, one more degree of unsaturation compared to compound $\mathbf{3}$. The ${ }^{1} \mathrm{H}$ - and ${ }^{13} \mathrm{C}-\mathrm{NMR}$ data for $\mathbf{4}$ were similar to those of $\mathbf{3}$ (Table 2), especially in rings B, C and D and the side-chain. The major difference was the appearance of a carbonyl carbon signal at $\delta_{\mathrm{C}} 216.4$ in 4 instead of the signal of 3-OH in 3, and as a consequence, a characteristic downfield shifted its vicinal methylene $\left[\left(\delta_{\mathrm{H}} 2.76(1 \mathrm{H}, \mathrm{td}, J=14.5,5.5 \mathrm{~Hz}), 2.25\right.\right.$ (1H, signal overlapping); $\left.\left.\delta_{\mathrm{C}} 34.8\right)\right]$, thus identified the structure of $\mathbf{4}$ as 3-oxo-tirucall-7-ene-3,20-dione.

Tetranortritrpenoids exemplified by compound $\mathbf{5}$ distributed widely in the genus Aphanamixis, while tirucallane-type nortriterpenoids were seldom encountered. It is noteworthy that compound $\mathbf{1}$ was the first tirucallane-type nortriterpenoids with the loss of the C-21 methyl, forming a transdouble bond at C-20 and C-22. Compound 2 featured a $\gamma$ lactone in side-chain and an $\alpha, \beta$-unsaturated ketone in ring A, which was also scarce in tetranortriterpenoids. Compounds 3 and $\mathbf{4}$ were $\mathrm{C}_{24}$ tirucallane triterpenoids formed by degradation of six carbons in the side-chain, which have never been reported as natural products. ${ }^{22}$

\section{Experimental}

General Procedures Optical rotations were determined with a JASCO P-1020 polarimeter ( $\mathrm{Na}$ filter, $\lambda=589 \mathrm{~nm}$ ) in $\mathrm{CHCl}_{3}$ solution. IR spectra were recorded on a Bruker Tensor 27 spectrometer with KBr-disks. Mass spectra were obtained on a MS Agilent 1100 Series LC/MSD Trap mass spectrometer (ESI-MS) and HR-ESI-MS was done on a Mariner time-offlight mass spectrometer with an electrospray interface, respectively. NMR spectra were recorded on Bruker ACF-500 NMR instrument $\left({ }^{1} \mathrm{H}: 500 \mathrm{MHz}\right.$, ${ }^{13} \mathrm{C}: 125 \mathrm{MHz}$ ) with tetramethylsilane (TMS) as internal standard. Silica gel (200 - 300 mesh, Qingdao Haiyang Chemical Co., Ltd., China), Sephadex LH-20 (Pharmacia, U.S.A.), and RP-C 18 (40-63 $\mu \mathrm{m}$, YMC, U.S.A.) were used for column chromatography. Preparative HPLC was carried out using Shimadzu with a Shimpak RP-C ${ }_{18}$ column $(20 \times 200 \mathrm{~mm}$, i.d.) and Multiple Wavelength detector. All solvents used were of analytical grad (Jiangsu Hanbang Sci. \& Tech. Co., Ltd., China). Fractions were monitored by TLC. Spots were visualized by heating silica gel plates immersed in vanillin- $\mathrm{H}_{2} \mathrm{SO}_{4}$ in ethanol.

Plant Material The stem barks of Aphanamixis grandifolia BL. were collected from Xishuangbanna, Yunnan Province, China in May 2008, and authenticated by Prof. Jingyun Cui of Xishuangbanna Tropical Garden, Chinese Academy of Sciences. A Voucher Specimen (No. AG-200805) has been deposited in the Department of Natural Medicinal Chemistry, China Pharmaceutical University.

Extraction and Isolation Air-dried stem barks of the plant material $(10 \mathrm{~kg})$ were extracted with $95 \%$ EtOH three times. The solvent was evaporated in vacuo, and the extracts were combined and concentrated, followed by suspension in water. The water layer was further extracted with $\mathrm{CHCl}_{3}$ and EtOAc. The $\mathrm{CHCl}_{3}$ fraction $(350 \mathrm{~g})$ was fractionated by column chromatography over D101 porous resin using gradient aqueous ethanol to give five fractions (fractions I-V).

Fraction I (15 g) was chromatographed on a RP-18 Si gel and eluted with $\mathrm{MeOH}-\mathrm{H}_{2} \mathrm{O}(4: 6-1: 0, \mathrm{v} / \mathrm{v})$ under grandient conditions, yielding five fractions (IA-IE). The fifth fraction IE $(2.2 \mathrm{~g})$ was fractioned into three parts over RP-18 Si gel with $\mathrm{MeOH}-\mathrm{H}_{2} \mathrm{O}$ again, then fraction IEA $(548 \mathrm{mg})$ was further purified on sephadex LH-20 (EtOAc-MeOH $1: 1, \mathrm{v} / \mathrm{v}$ ) and applied to a RP-18 Si gel column (eluted with acetone- $\mathrm{H}_{2} \mathrm{O} 3: 7, \mathrm{v} / \mathrm{v}$ ) to yield 5 (15 mg).

Fraction II ( $150 \mathrm{~g})$ was fractionated to 11 fractions using chromatography on silica gel eluted with $0-10 \% \mathrm{MeOH}$ in $\mathrm{CH}_{2} \mathrm{Cl}_{2}$. The third fraction IIC $(30 \mathrm{~g})$ was separated eight fractions over RP-18 Si gel and eluted with $\mathrm{MeOH}-\mathrm{H}_{2} \mathrm{O}(6: 4-1: 0)$ under gradient conditions. Then, the fraction IICB $(15 \mathrm{~g})$ was chromatographed on a $\mathrm{Si}$ gel column eluted with a mixture of petroleum ether-EtOAc $(25: 1-2: 1, \mathrm{v} / \mathrm{v})$ in gradient to give seven major fractions. Fraction IICBC $(2.18 \mathrm{~g})$ was separated over a reversed-phase Si gel column $\left(\mathrm{MeOH}-\mathrm{H}_{2} \mathrm{O}, 80: 20\right.$, v/v) to afford three major fractions, IICBC 1 (241 mg), IICBC 2 (925 mg), and IICBC 3 (524 mg). Fractions IICBC 1IICBC 3 were respectively purified by column chromatography over Sephadex LH-20 $\left(\mathrm{CH}_{2} \mathrm{Cl}_{2}-\mathrm{MeOH}, 1: 1, \mathrm{v} / \mathrm{v}\right)$. Finally, the fraction IICBC 2 $(530 \mathrm{mg})$ was further purified by successive RP-18 preparative HPLC with $\mathrm{MeOH}-\mathrm{H}_{2} \mathrm{O}(85 \%, \mathrm{v} / \mathrm{v})$ to obtain $2\left(16.9 \mathrm{mg}, t_{\mathrm{R}} 22.8 \mathrm{~min}\right)$ and $3\left(5.5 \mathrm{mg}, t_{\mathrm{R}}\right.$ $24.3 \mathrm{~min})$, the fraction IICBC $3(446 \mathrm{mg})$ was then subjected to preparative $\mathrm{HPLC}$ with $\mathrm{CH}_{3} \mathrm{CN}-\mathrm{H}_{2} \mathrm{O}\left(88 \%\right.$, v/v) to yield 4 (12.7 mg, $\left.t_{\mathrm{R}} 19.5 \mathrm{~min}\right)$. Fraction IICBD $(3.5 \mathrm{~g})$ was subjected to a $\mathrm{Si}$ gel column eluted with a mixture of petroleum ether-EtOAc $(8: 1, \mathrm{v} / \mathrm{v})$ to afford two fractions, IICBD 1 $(950 \mathrm{mg})$, and IICBD $2(713 \mathrm{mg})$. Fraction IICBD 1 was purified by reversed-phase octadecyl silica gel (ODS) and Sephadex LH-20 $\left(\mathrm{CH}_{2} \mathrm{Cl}_{2}-\right.$ $\mathrm{MeOH}, 1: 1, \mathrm{v} / \mathrm{v})$ chromatography and then subjected to preparative HPLC to yield 1 (14.3 $\left.\mathrm{mg}, t_{\mathrm{R}} 20.4 \mathrm{~min}\right)$ with $\mathrm{MeOH}-\mathrm{H}_{2} \mathrm{O}(90 \%$, v/v).

24,25-Epoxy-tirucall-7,20(E)-diene-3,23-dione (1): White, amorphous powder; $[\alpha]_{\mathrm{D}}^{27}-2.1\left(c=0.73, \mathrm{CHCl}_{3}\right) ; \mathrm{CD} \lambda_{\max }\left(c=0.72, \mathrm{CH}_{3} \mathrm{CN}\right) \mathrm{nm}(\Delta \varepsilon)$ : 191 (+23.4), 211 (-16.2), 243 (+16.7); IR (KBr) $v_{\max } \mathrm{cm}^{-1}: 3447,2967$, 2866, 2351, 2320, 1708, 1682, 1622, 1456, 1387, 648; ${ }^{1} \mathrm{H}-$ and ${ }^{13} \mathrm{C}-\mathrm{NMR}$ spectral data: see Table 1; ESI-MS $m / z 461.3[\mathrm{M}+\mathrm{Na}]^{+}, 899.6[2 \mathrm{M}+\mathrm{Na}]^{+}$; HR-ESI-MS $m / z 461.3028[\mathrm{M}+\mathrm{Na}]^{+}$(Calcd for $\mathrm{C}_{29} \mathrm{H}_{42} \mathrm{O}_{3} \mathrm{Na}, 461.3026$ ).

24,25,26,27-Tetranortirucall-1,7-diene-23(21)-lactone (2): White, amorphous powder; $[\alpha]_{\mathrm{D}}^{27}-2.1\left(c=0.19, \mathrm{CHCl}_{3}\right)$; IR $(\mathrm{KBr}) v_{\max } \mathrm{cm}^{-1} 3454$, 2961, 2878, 1783, 1707, 1675, 1474, 1382, 1366, 1179, 1038, 1019, 827, 717, 657; ${ }^{1} \mathrm{H}$ - and ${ }^{13} \mathrm{C}-\mathrm{NMR}$ see Table 1; HR-ESI-MS $\mathrm{m} / \mathrm{z} 419.2570$ $[\mathrm{M}+\mathrm{Na}]^{+}\left(\right.$Calcd for $\left.\mathrm{C}_{26} \mathrm{H}_{36} \mathrm{O}_{3} \mathrm{Na}, 419.2557\right)$.

$3 \alpha$-Hydroxy-tirucall-7-ene-20-one (3): White, amorphous powder; $[\alpha]_{\mathrm{D}}^{27}$ -94.1 $\left(c=0.35, \mathrm{CHCl}_{3}\right)$; IR (KBr) $v_{\max } \mathrm{cm}^{-1}: 3557,3523,2964,2939$, 2879, 2841, 2353, 2320, 1698, 1471, 1385, 1362, 1209, 1183, 1040, 829, 644; ${ }^{1} \mathrm{H}$ - and ${ }^{13} \mathrm{C}-\mathrm{NMR}$ spectral data: see Table 2; ESI-MS $\mathrm{m} / \mathrm{z} 359.3$ $[\mathrm{M}+\mathrm{H}]^{+}$; HR-ESI-MS m/z $381.2769[\mathrm{M}+\mathrm{Na}]^{+}\left(\mathrm{Calcd}\right.$ for $\mathrm{C}_{24} \mathrm{H}_{38} \mathrm{O}_{2} \mathrm{Na}$, 381.2764).

3-Oxo-tirucall-7-ene-3,20-dione (4): White, amorphous powder; $[\alpha]_{\mathrm{D}}^{27}$ $-161.9\left(c=0.11, \mathrm{CHCl}_{3}\right)$; IR $(\mathrm{KBr}) v_{\max } \mathrm{cm}^{-1}: 3445,2965,2882,2352$, $1786,1706,1642,1472,1387,1360,1205,1172,650,581 ;{ }^{1} \mathrm{H}-$ and ${ }^{13} \mathrm{C}-$ 
NMR spectral data: see Table 2; ESI-MS $m / z$ 379.2 $[\mathrm{M}+\mathrm{Na}]^{+}, 735.5$ $[2 \mathrm{M}+\mathrm{Na}]^{+}$; HR-ESI-MS $m / z$ 379.2609 $[\mathrm{M}+\mathrm{Na}]^{+}\left(\mathrm{Calcd}\right.$ for $\mathrm{C}_{24} \mathrm{H}_{36} \mathrm{O}_{2} \mathrm{Na}$, 379.2608).

Mobasol (5): White, amorphous powder; ${ }^{1} \mathrm{H}-\mathrm{NMR}\left(500 \mathrm{MHz}, \mathrm{CDCl}_{3}\right) \delta_{\mathrm{H}}$ : $6.94(1 \mathrm{H}, \mathrm{d}, J=12.9 \mathrm{~Hz}, \mathrm{H}-1), 6.32(1 \mathrm{H}, \mathrm{d}, J=12.9 \mathrm{~Hz}, \mathrm{H}-2), 3.42(1 \mathrm{H}, \mathrm{d}$, $J=8.1 \mathrm{~Hz}, \mathrm{H}-5), 2.40(1 \mathrm{H}, \mathrm{d}, J=9.0 \mathrm{~Hz}, \mathrm{H}-6 \mathrm{a}), 2.28(1 \mathrm{H}, \mathrm{d}, J=14.1 \mathrm{~Hz}, \mathrm{H}-$ 6b), 3.12 (1H, d, $J=7.5 \mathrm{~Hz}, \mathrm{H}-9), 5.76$ (1H, dd, $J=11.0,7.5 \mathrm{~Hz}, \mathrm{H}-11), 6.02$ $(1 \mathrm{H}, \mathrm{d}, J=11.0 \mathrm{~Hz}, \mathrm{H}-12), 3.91(1 \mathrm{H}, \mathrm{s}, \mathrm{H}-15), 1.84(1 \mathrm{H}, \mathrm{dd}, J=14.0$, $10.8 \mathrm{~Hz}, \mathrm{H}-16 \alpha), 2.28(1 \mathrm{H}, \mathrm{dd}, J=14.0,6.9 \mathrm{~Hz}, \mathrm{H}-16 \beta), 3.07(1 \mathrm{H}, \mathrm{dd}$, $J=10.5,6.9 \mathrm{~Hz}, \mathrm{H}-17), 0.94$ (3H, s, H-18), 1.00 (3H, s, H-19), 7.11 (1H, s, H-21), 6.14 (1H, s, H-22), 7.33 (1H, s, H-23), 1.34 (3H, s, H-28), $4.68(1 \mathrm{H}$, d, $J=11.7 \mathrm{~Hz}, \mathrm{H}-29 \mathrm{a}), 4.35$ (1H, d, $J=11.7 \mathrm{~Hz}, \mathrm{H}-29 \mathrm{~b}), 5.40$ (1H, s, H-30a), $5.27(1 \mathrm{H}, \mathrm{s}, \mathrm{H}-30 \mathrm{~b}), 1.23\left(1 \mathrm{H}, \mathrm{m}, \mathrm{H}-3^{\prime}\right), 1.35\left(2 \mathrm{H}, \mathrm{m}, \mathrm{H}-4^{\prime}\right), 0.68(3 \mathrm{H}, \mathrm{d}$ $\left.J=6.3 \mathrm{~Hz}, \mathrm{H}-5^{\prime}\right), 0.82\left(3 \mathrm{H}, \mathrm{t}, J=7.2,6.9 \mathrm{~Hz}, \mathrm{H}-6^{\prime}\right), 8.07(1 \mathrm{H}, \mathrm{s}, \mathrm{HCOOR})$, $3.73(3 \mathrm{H}, \mathrm{s}, \mathrm{OMe})$ and $2.10(3 \mathrm{H}, \mathrm{s}, \mathrm{OAc}) .{ }^{13} \mathrm{C}-\mathrm{NMR}\left(125 \mathrm{MHz}, \mathrm{CDCl}_{3}\right) \delta_{\mathrm{C}}$ : 147.4 (C-1), 122.7 (C-2), 165.4 (C-3), 84.0 (C-4), 50.4 (C-5), 34.7 (C-6), 173.1 (C-7), 136.1 (C-8), 53.2 (C-9), 45.4 (C-10), 69.8 (C-11), 72.9 (C-12), 46.0 (C-13), 70.8 (C-14), 59.7 (C-15), 33.8 (C-16), 37.6 (C-17), 12.6 (C-18), 23.7 (C-19), 121.7 (C-20), 140.4 (C-21), 111.0 (C-22), 142.7 (C-23), 24.6 (C-28), 63.8 (C-29), 121.5 (C-30), $175.0\left(\mathrm{C}-1^{\prime}\right), 75.2\left(\mathrm{C}-2^{\prime}\right), 37.8\left(\mathrm{C}-3^{\prime}\right)$, 26.2 (C-4'), 11.7 (C-5'), 13.5 (C-6'), 159.7 (HCOOR), 52.5 (OMe), 20.7 $(\mathrm{OAc}-\mathrm{Me})$ and 170.3 (OAc-CO). ESI-MS $\mathrm{m} / \mathrm{z} 721.6[\mathrm{M}+\mathrm{Cl}]^{-} ; 687.2$ $[\mathrm{M}+\mathrm{H}]^{+}, 704.3\left[\mathrm{M}+\mathrm{NH}_{4}\right]^{+}$and $709.3[\mathrm{M}+\mathrm{Na}]^{+}$.

Acknowledgements This research work was supported by the Cultivation Fund of the Key Scientific and Technical Innovation Project, Ministry of Education of China (707033), and the Scaling Project for Innovation Scholars, Natural Science Foundation of Jiangsu Province, China (BK2008039).

\section{References}

1) Brown D. A., Taylor D. A. H., Phytochemistry, 17, 1995-1999 (1978).

2) King T. J., Taylor D. A. H., Phytochemistry, 22, 307 (1983).

3) Mulholland D. A., Naidoo N., Phytochemistry, 51, 927-930 (1999).

4) Polonsky J., Varon Z., Arnoux B., Pascard C., Pettit G. R., Schmidt J.
M., J. Am. Chem. Soc., 100, $7731-7733$ (1978).

5) Polonsky J., Varon Z., Arnoux B., Pascard C., Pettit G. R., Schmidt J. M., Lange L. M., J. Am. Chem. Soc., 100, 2575-2576 (1978).

6) Kundu A. B., Ray S., Chatterjee A., Phytochemistry, 24, 2123-2125 (1985).

7) Chandrasekharan S., Chakraborty T., J. Indian Chem. Soc., 45, 208 (1968).

8) Nishizawa M., Inoue A., Hayashi Y., Sastrapradja S., Kosela S., Iwashita T., J. Org. Chem., 49, 3660-3662 (1984).

9) Mariezcurrena R. A., Acta Cryst. B, 34, 2322-2324 (1978).

10) Luo J., Wang J. S., Wang X. B., Huang X. F., Luo J. G., and Kong L. Y., Tetrahedron, 65, 3425-3431 (2009).

11) Luo J., Wang J. S., Luo J. G., Wang X. B., Kong L. Y., Org. Lett., 11, 2281-2284 (2009).

12) Yang M. H., Wang J. S., Luo J. G., Wang X. B., Kong L. Y., J. Nat. Prod., 72, 2014-2018 (2009).

13) Adul G. O., Bentley M. D., Benson B. W., Huang F. Y., Gelbaum L., Hassanali A., J. Nat. Prod., 56, 1414-1417 (1993).

14) Chen S. K., Chen B. Y., Li H., "Flora Reipublicae Popularis Sinicae (Zhongguo Zhiwu Zhi)," Vol. 43, Science Press, Beijing, 1997, p. 75.

15) Jolad S. D., Hoffmann J. J., Schram K. H., Cole J. R., Tempesta M. S. Bates R. B., J. Org. Chem., 45, 3132-3135 (1980).

16) Jolad S. D., Hoffmann J. J., Schram K. H., Cole J. R., Tempesta M. S., Bates R. B., J. Org. Chem., 46, 4085-4088 (1981).

17) Wang H., Zhang X. F., Yang S. M., Luo X. D., Acta Bot. Sin., 46 $1256-1260$ (2004)

18) Onan K. D., Lavie D., Vincent V. V., Zelnik R., J. Chem. Soc., Perkin Trans. 1, 1985, 323-325 (1985).

19) Harada N., Iwabuchi J., Yokota Y., Uda H., Nakanishi K., J. Am. Chem. Soc., 103, 5590-5591 (1981).

20) Koreeda M., Weiss G., Nakanishi K. J. Am. Chem. Soc., 95, 239-240 (1973).

21) Yang S. M., Ma Y. B., Luo X. D., Wu S. H., Wu D. G., Chin. Chem. Lett., 15, 1187-1190 (2004).

22) William W. E., George V. L., J. Org. Chem., 31, 3434-3435 (1966). 